\title{
The Path Selections of the Resource-based Cities Transformation in China
}

\author{
Jinhuang Mao ${ }^{1}$ \\ ${ }^{1}$ School of Economics, Northwest University for Nationalities, Lanzhou, China \\ Correspondence: Jinhuang Mao, School of Economics, Northwest University for Nationalities, Lanzhou 730124, \\ China. E-mail: maojinhuang@126.com
}

Received: March 14, 2014

Accepted: March 24, 2014

Online Published: April 7, 2014

doi:10.5430/ijfr.v5n2p171

URL: http://dx.doi.org/10.5430/ijfr.v5n2p171

This work was supported by the Fundamental Research Funds for the Central Universities of Northwest University for Nationalities (Grant No: ZYZ2011016).

\begin{abstract}
The transformation of resource-based cities, a worldwide problem, is a broad, cross-cutting and complex issue, which involves many fields of economics, sociology, geography, mining science and ecology. Therefore, the development of resource-based cities in China has been a top priority among researchers. In this paper, the author will work out the best pattern and path of resource-based cities by researching on transition modes, approaches and policies.
\end{abstract}

Keywords: resource-based cities, transformation, path selections

\section{Introduction}

Resource-based cities develop on the basis of natural resources. These cities usually take exploration and process local resources, such as minerals, oil and forests, which resulted in a single industrial structure. That consists of the urban system of special groups, locally non-renewable natural resource's extraction and initial processing of the pillar industries. The prominent features of these cities are: the first is primary urban industry, that is to say, the leading industry of cities is the extraction industries and the primary processing industries established around the developing of resource; the second one is that single, major function of the city is to provide mine products and processed products and other resource-based products for the society. Due to the characteristics of resource development industry, the development of resource-based industry is unsustainable. Only through scientific planning and industrial design of resource-based cities, can we achieve a reasonably industrial layout and the sustainable development of cities.

According to product life-cycle theories, resource area usually experiences four stages of development-introduction, growth, maturity and decline. Now there are about 400 mines in our country and mines cities are going to bankrupt because of exhausted resources. Since those undegenerated resources are depleting, these cities are facing many problems, such as unbalanced industries mix, high rate of unemployment, seriously damaged ecological environment and the pressure to keep social stability. The urgent problem with resource-based cities is to avert resources into keeping curse and to realize industry conversion for the sustainable development of these cities while resource are used up gradually.

The ultimate aim of achieving industrial structure transition of resource-based cities is to accelerate urban economic development, to encourage reasonable and sustainable resource utilization, to protect ecological environment and to speed up all-round social progress. In light of this objective, the evaluation of the economic transformation and the performance of resource-dependent cities should also take these four dimensions into consideration.

\section{The Characteristics of Resource-based Cities Development}

2.1 Cities Development Is Highly Dependent on Resource-based Industries

Resource-based industry is the leading industry or pillar industry in resource-based cities. There have formed a high 
correlation chains in the cities. In resource-based cities, they are all based on resource development, including the spatial layout of the city, the energy and power, the road transport, the telecommunications, sanitation and other infrastructure construction and housing, schools, hospitals and other facilities construction, and so on. The resource-based cities, resource-based industries and resource-based enterprises rely on each other, rising and declining together. Resource-based industry, as the leading industry, is to support the economic development of the city's dominant force and is the main strength of the performance of the urban economy, urban GDP, output, employment, fiscal revenue leading creators.

\subsection{The Single Type, Super-heavy, Steady-state Model of Industries Structure}

The single structure, the major heavy industry, extractive industry and raw materials industry are in high proportion in resource-based economic structure. It is the most important features in resource-based cities, except for processing industry. And most of them are the relatively low degree of processing products in the front of the industry chain. The primary products take superiority in product structure. High-tech industry lags behind and the tertiary industry is developing but weighted. .

\subsection{The Poor Quality of Environment and the Pressure of Governing of Environment}

Mining industrial economic activities are serious environmental pollution and destruction of industry, especially in coal mining, refining and petrochemical processing, iron and non-ferrous metals, and other mineral mining and processing industry. The natural landscape, the atmosphere and water quality of the city and human production are influenced seriously. Therefore, the problems that the environment of resource-based cities is facing are beyond those of other cities.

\section{The Inevitability of Resource-based Cities Transformation}

\subsection{It Is Necessary to Achieve the Objective Requirements of Sustainable Development}

Industrial transformation is inevitable for the sustainable development of resource-based cities. At present, the industry transformation of resources city basically belong to passive industry transformation, namely, resource depletion has been or is about to make the development of the city be in trouble. Since the use of non-renewable natural resources cannot go from mining to industrial transformation, we have to open up a new road, and this is the industry transformation. According to the direct understanding of sustainable development, it is not difficult to draw the two principles. First, it is the development principle. Development is the common human right, and the right should be continued on the condition that the right to develop must take into account future generations. Second, it is the principle of sustainability. In other words, the pursuit of human development must be sustainable. To realize this, you must change the way of simply increasing investment and increasing consumption in order to achieve the development of the traditional development model and the development of natural resource. At the same time, human consumption should be controlled and the consumers should oppose extravagance and waste of all kinds.

\subsection{The Resource-based Urban Transformation Is the Key to Improving the Competitiveness of the City}

The urban fundamental competition is the leading industry competition. With the resource-based industry changing most resource-based cities experienced the situation from the boom to doom. But the city and the people are different. In fact, no matter how depressed the city is, it is unlikely to be dead as long as humans exist and the ups and downs of urban space can be transformed. In some cities, you can also be rejuvenated, reborn, but the city requires that the urban economy should be boosted. Non-renewable resources are exhaustible natural resource-based industries that enhance decisively limited competitiveness of space. Therefore, the key to enhance the competitiveness of resource-based cities is leading industry in transition. Only through transformation, can upgrading the industrial structure improve the competitiveness of resource-based city.

\subsection{The Transformation of Resource-based City Is the Industrial Economy to the Inevitable Changes in the New Economic Era}

With the advent of the industrial age, manufacturing-based economy comes into being. The rapid development of light industry accounts for the huge proportion of the manufacturing, with resource-based cities initially produced, with the rapid development of heavy industry, and dominates the manufacturing of resource-based cities that are developing rapidly and reach its peak. With the rise of new industries, the status of heavy industry began to decline because the evolution of human civilization from the extractive use of natural chemicals times and to artificial creation and use of chemical substances in the era of the status of the resource-based cities are challenged and make resources cities become inevitable. 


\section{Resource-based Urban Transformation Path}

\subsection{The Restructuring of Urban Space}

In terms of transformation of resource-based cities, we must start from the big picture, which is aimed to establish the scale of coordinative, complementary and spatial layout that features reasonably closely around the metropolitan area of resource-based cities, highways and other infrastructure, including many small cities and small towns that form coordinated networks of urban development. There is a close relationship between technical and economic aspects in the network. Traditionally speaking, with continuous economic development and the improvement in traffic, communications and other infrastructures, accelerated development has been a trend. The most important tasks are adjusting the industrial structure and developing modern agriculture and urban agriculture. Then we should increase the equipment manufacturing industry and high-tech industry development efforts to gradually lower the technical content, at odds with the city's industrial development objectives transferred out ; vigorously develop the tertiary industry in all aspects of modern finance, logistics, information, tourism, etc. can form a strong support for the metropolitan area in the economy.

\subsection{The Adjustment of industrial Structure}

As a starting point in resource-based urban characteristics, through new industrialization, high technical industrial scale, modern urban services, characteristics of peri-urban agriculture and equipment manufacturing group and the adjustment of industrial structure, promote the transformation of resource-based cities, and actively explore the need to adjust industry, strictly control of high pollution, high energy consumption and development (water) industry, considering the evolution of the law of another country (city) industrialization process demonstrated by the leading industry. Special positioning, optimizing industrial structure of the economic development and resource-based cities in china particularity stages of economic structure, building a new economic growth point. For necessary or inevitable form resource-based cities or towns, to fully understand the development of resource-based cities unsustainable and the necessity of industry transformation, and history is any guide, take the initiative to industry transformation. By optimizing the industrial structure, dominated by natural resources exploitation and processing industry, on this basis to develop a diversified economy actively, vigorously foster the third industry, achieved step by step in an industry as the leading factor, a few do pillar industry, from a single resources industry into a diversified industrial economy system, the main contradiction resolve in the process of urban development, avoid passive industry transformation the disadvantages of high cost, difficult and risky, realize the comprehensive sustainable development of urban economy.

\subsection{The Transformation of Resource-based Cities}

Government plays an irreplaceable role in the market economy, and this effect is mainly achieved through policy. Functional policy is mainly manifested in two aspects: on the one hand, to make up for the lack of market mechanisms in the field of competition in the market "failure" to implement remedial and corrective, as demonstrated by the induction of short-term individual interests and the interests of economic entities reverted to the community common interests and long-term interests; on the other hand, in non-competitive areas, government policies play a fundamental role in the allocation of resources, market mechanisms from external oversight role of government (mainly for the market players oversight policy body) to promote government action efficient allocation of resources. In conclusion, the government should develop the resource-based cities transition process in favor of restructuring fiscal policy, industrial policy and investment policy. The government also actively promote the transformation of resource-based cities to achieve sustainable development of resource-based cities

To realize the transition of Resource-based cities, in accordance with objective laws, one must construct the recent restructuring goals and long-term mating composite target system. On the other hand, urban transformation must be combined with economic restructuring and sustainable development. We should reasonably handle the relationship between government and social participation. Therefore, the overall coordination, is a powerful guarantee for promoting the development of resource-based city transformation. Promoting the development of resource-based city transformation should give full play to the leading role of the government at all levels. Everyone also need to actively participate in the transformation and effectively mobilize the social from all walks of life force, which will fully release the vitality of urban development so that promoting the development of transformation can make greater achievements.

\section{Conclusions}

The transformation of resource-based cities urgently need some special policies, such as industrial policy, fiscal policy, environmental policy, employment and social security policies, and regional development and investment 
policies, which will aid industrial structure conversion. The following are the effective measures: promoting the development of non-resource industries; establishing the fund, including aging converting abandoned mines fund, the special fund of resources city transformation and Special Workers Social Security Fund; raising the proportion of fiscal transfer payment; formulating the training programs for workers in transition and re-employment programs; focusing on solving the economic transformation of resource-based cities, social security and environmental sustainability; achieving full employment of labor . In terms of investment policy, the focus is to develop the private economy and encourage the development of SMEs. On the one hand, the government must construct the target system that are recent goals and long-term. On the other hand, urban transformation must be combined with economic restructuring and then the development of resource-based cities can be sustainable.

\section{References}

Button, K. J. (1982). Urban Economics: Theory and Policy. The MACMILLAN Press.

Clark, C. (1940). The Condition of Economic Progress. London.

Freeman, C. (1982). The Economics of Industrial Innovation. The MIT Press.

Geiger, R. (1986). To Advance Knowledge: The Growth of American Research Universities. 1900-1940. New York: Oxford University Press.

Graham, H. D., \& Diamond, N. (1997). The Rise of American Research Universities. Baltimore: Johns Hopkins University Press.

Jackson, R. T. (1987). Commuter mining and the Kidston gold mine: goodbye to miningtown. Geography, 72 , $162-165$

Kuznets, S. (1985). Economic Growth of Nations: Total Output and Production Structure. The Commercial Press, Trans. Chang Xun, Beijing, pp. 111-112.

Mowery, D.C., \& Rosenberg, N. (1993). The U.S. National Innovation System. In Nelson, R.R. (Ed.), National Innovation Systems: A Comparative Analysis. New York: Oxford University Press.

West, A. (1992). Innovation Strategy. Prentice Hall Ltd. 